\title{
The effect of 8-week different-intensity walking exercises on serum hepcidin, IL-6, and iron metabolism in pre-menopausal women
}

\author{
G Buyukyazi ${ }^{1}$, C Ulman², A Çelik ${ }^{1}$, C Çetinkaya ${ }^{1}$, AR Şişman ${ }^{3}$, \\ D Çimrin ${ }^{3}$, Y Doğru ${ }^{4}$, D Kaya ${ }^{5}$ \\ ${ }^{1}$ School of Sport Sciences and Technology, Dokuz Eylül University, Izmir, Turkey \\ ${ }^{2}$ Department of Biochemistry, Faculty of Medicine, Celal Bayar University, Manisa, Turkey \\ ${ }^{3}$ Department of Biochemistry, Faculty of Medicine, Dokuz Eylül University, Izmir, Turkey \\ ${ }^{4}$ Department of Biochemistry, School of Physical Education and Sports, Ege University, Izmir, Turkey \\ ${ }^{5}$ Department of Cardiology, Faculty of Medicine, Dokuz Eylül University, Izmir, Turkey
}

Received: March 26, 2016

Accepted: November 29, 2016

\begin{abstract}
Objective: Hepcidin may be an important mediator in exercise-induced iron deficiency. Despite the studies investigating acute exercise effects on hepcidin and markers of iron metabolism, we found no studies examining the chronic effects of walking exercises (WE) on hepcidin and markers of iron metabolism in premenopausal women. The chronic effects of two 8-week different-intensity WE on hepcidin, interleukin 6 (IL-6), and markers of iron metabolism in pre-menopausal women were examined. Methods: Exercise groups (EG) [moderate tempo walking group (MTWG), $n=11$; brisk walking group (BWG), $n=11$ ] walked 3 days/week, starting from 30 to $51 \mathrm{~min}$. Control group (CG; $n=8$ ) did not perform any exercises. BWG walked at $\sim 70 \%-75 \%$; MTWG at $~ 50 \%-55 \%$ of $\mathrm{HRR}_{\max } \cdot \mathrm{VO}_{2 \max }$, hepcidin, IL-6, and iron metabolism markers were determined before and after the intervention. Results: $\mathrm{VO}_{2 \max }$ increased in both EGs, favoring the BWG. Hepcidin increased in the BWG $(p<0.01)$ and CG $(p<0.05)$. IL-6 decreased in the BWG and the MTWG $(p<0.05 ; p<0.01)$. While iron, ferritin, transferrin, and transferrin saturation levels did not change in any group, total iron binding capacity $(p<0.05)$, red blood cells $(p<0.05)$, and hematocrit $(p<0.01)$ increased only in the BWG. Conclusion: Both WE types may be useful to prevent inflammation. However, brisk walking is advisable due to the positive changes in $\mathrm{VO}_{2 \max }$ and some iron metabolism parameters, which may contribute to prevent iron deficiency. The increase in hepcidin levels remains unclear and necessitates further studies.
\end{abstract}

Keywords: hepcidin, IL-6, iron metabolism, pre-menopausal women, walking

\section{Introduction}

Iron is an essential element for most of the processes in our body. It has important roles in oxygen transport and storage [forming part of hemoglobin $(\mathrm{Hb})$ and myoglobin] and in the electron transport chain and DNA synthesis (6). These functions make iron the most important factor related to human sports performance. While iron homeostasis is essential for effective energy metabolism, iron depletion reduces performance capacity. Transferrin transports iron in blood whereas ferritin stores it within cells. Hepcidin is synthesized by the liver and it controls iron metabolism. Hepcidin blocks iron absorption from the duodenum

Corresponding author: Prof. Dr. Gurbuz Buyukyazi

School of Sport Sciences and Technology, Dokuz Eylül University

Sağlık Yerleşkesi, İnciraltt, 35340 Izmir, Turkey

Phone: +90 53346353 88; Fax: +90 23241297 19; E-mail: gurbuzbuyukyazi@gmail.com 
and limits iron accumulation in the body (12), which leads to iron deficiency. An increase in inflammation-induced hepcidin may cause a rapid decrease in plasma iron concentrations, which will eventually decrease $\mathrm{Hb}$ synthesis (27). Women athletes are at a particular risk of depleting their iron stores. If not treated, iron deficiency may lead to iron deficiency anemia (7). Therefore, understanding hepcidin response associated with physical exercise may help explain anemia and iron deficiency frequently affecting athletes (19). However, detection and quantification of hepcidin in plasma and serum is difficult; but, pro-hepcidin measurement using enzyme-linked immunosorbent assay (ELISA) is non-invasive and easy to perform, and thus appropriate for routine work $(17,23)$. There is also evidence in the literature that pro-hepcidin levels are a reliable indicator of hepcidin levels and activity $(14,45)$ and there is $92 \%$ correlation between hepcidin and its precursor pro-hepcidin (46). Moreover, we could not find studies examining the effects of physical exercise on pro-hepcidin levels; therefore, relying on this high correlation between these two markers, we compared our findings with those of hepcidin throughout the text.

Skeletal muscles were found to produce and release myokines during exercise, exerting an anti-inflammatory effect, and acting as energy sensors (32). One of these myokines is interleukin 6 (IL-6). The mode, intensity, and duration of exercise have been found to increase the concentrations of cytokines $(11,30)$. IL-6 causes an increase in blood hepcidin concentration. In recent years, the studies conducted with adults have revealed that both single and regular exercises are the cause in the rise of blood hepcidin, diminishing dietary iron absorption and body iron stores $(3,33)$. In addition, studies investigating the acute postexercise kinetics of hepcidin and associations with iron metabolism in athletes report about elevated hepcidin levels $24 \mathrm{~h}$ after exercise, preceded by acute increase in serum iron and inflammation parameters $(34,36,48)$. On the other hand, Karl et al. (15) showed that serum hepcidin concentrations were not affected by 9 weeks of basic combat training for female soldiers but were associated with iron status and inflammation. Auersperger et al. (4) suggested that serum hepcidin and sTfR were affected after 8 weeks of endurance running in women without any positive relation with inflammation.

Typical characteristics of anemia in inflammation are shorter life of erythrocytes, low serum concentrations of iron and transferrin, and elevated levels of ferritin (28). A low level of iron is an important cause of reduced exercise capacity in athletes. A $1-2 \mathrm{~g} \%$ decrease in blood $\mathrm{Hb}$ concentration may lead to a $20 \%$ reduction in exercise capacity (13). Therefore, exercise-induced changes in iron metabolism should be analyzed in detail. Even though exercise can increase erythropoietic activity in bone marrow (38), intensive training was found to have negative effects on erythrocyte numbers, Hb levels, and hematocrit (Hct) values $(19,47)$. The main reason for this may be the reduced iron absorption in small intestine and the decreased iron export to the circulation from parenchymal cells and macrophages.

Despite the accumulated research findings related to acute effects of exercise on hepcidin, IL-6, and iron metabolism markers $(34-36,42,48)$, there is limited data about the chronic effect of exercise on these parameters $(4,15)$. Moreover, to our knowledge, there are no studies examining the chronic effects of walking exercises (WE) on hepcidin, IL-6, and iron metabolism markers. Therefore, the aim of this study is to examine the chronic effects of two 8-week different-intensity WE on hepcidin, IL-6, and markers of iron metabolism in premenopausal women. We hypothesize that 8 weeks of brisk WE have more beneficial effects than moderate walking for reducing inflammation, protecting from anemia and metabolic diseases. 


\section{Materials and Methods}

\section{Subject selection}

This study examined moderately active females (2-3 sessions/week) in reproductive age and without history of gynecological surgery. All participants were informed about the purpose, potential benefits, and possible risks of the study protocol; then, they all gave written informed consent. Participants were invited to the study if they met the following criteria: having regular menses within the 12 months preceding the study; not using iron supplements; not being under regular use of medication. Participants having a history or diagnosed cardiovascular disease, endocrine or metabolic disorders, muscular-skeletal problems were excluded. The participants meeting the inclusion criteria chose to take part in either the experimental group $(n=22)$ or control group (CG; $n=8$ ). Then, the exercise group (EG) was randomly divided into brisk walking group (BWG; $n=11$ ) and moderate tempo walking group (MTWG; $n=11$ ) (Table I). Baseline laboratory analysis including electrocardiography and body compositions revealed no acute or chronic inflammatory condition in any of the participants. Baseline iron and ferritin levels of the groups were not significantly different from each other. Participants were warned not to take any other form of physical exercise and not to change their eating habits during the intervention. The study was approved by the Ethical Council of Dokuz Eylül University, Faculty of Medicine and conducted in accordance with the principles of Declaration of Helsinki.

\section{Study design}

All tests and analyses were performed at the beginning and at the end of the intervention period (24-48 $\mathrm{h}$ after the walking program). Blood analyses were carried out by the experts $24 \mathrm{~h}$ following the exercise program at the same time in all groups $\left(8.00-10.00\right.$ a.m.). $\mathrm{VO}_{2 \max }$ and the other measurements were conducted $48 \mathrm{~h}$ following the training program so that the subjects had time for recovery. Body composition was measured using bioelectrical impedance analyzer (InBody 230, Biospace Co. Ltd., Seoul, Korea). Indirect maximal oxygen consumption $\left(\mathrm{VO}_{2 \max }\right)$ was determined with $2 \mathrm{~km}$ walking test using the following equation developed for women (18):

$$
116.2-2.98 \text { duration }(\mathrm{min})-0.11 \times \mathrm{HR}-0.14 \text { age }-0.39 \mathrm{BMI} \text {. }
$$

Subjects were warned not to perform any physical activity within $48 \mathrm{~h}$ preceding the assessment day.

Table I. General characteristics of participants at baseline

\begin{tabular}{|l|c|c|c|c|c|c|}
\hline \multirow{2}{*}{ Parameters } & \multicolumn{2}{|c|}{ BWG $(n=11)$} & \multicolumn{2}{c|}{ MTWG $(n=11)$} & \multicolumn{2}{c|}{ CG $(n=8)$} \\
\cline { 2 - 7 } & Median & Min-Max & Median & Min-Max & Median & Min-Max \\
\hline Age (years) & 41.0 & $33-50$ & 38.0 & $30-46$ & 43.5 & $41-47$ \\
\hline Height $(\mathrm{cm})$ & 160 & $157-168$ & 163 & $152-172$ & 159 & $154-168$ \\
\hline Body weight $(\mathrm{kg})$ & 69.5 & $60.5-82.8$ & 69.1 & $54-104.1$ & 64.6 & $53.6-75.4$ \\
\hline BMI $\left(\mathrm{kg} / \mathrm{m}^{2}\right)$ & 26.2 & $23.6-29.6$ & 26.3 & $22.2-40.2$ & 25.3 & $20.9-30.1$ \\
\hline Body fat $(\mathrm{kg})$ & 26.0 & $21.5-34.3$ & 26.3 & $15.6-51.6$ & 25.5 & $14.1-32.7$ \\
\hline VO $_{2 \mathrm{max}}(\mathrm{ml} / \mathrm{kg} / \mathrm{min})$ & 34.1 & $28.5-39.4$ & 31.4 & $20.9-38.5$ & 23.9 & $14.4-29.3$ \\
\hline
\end{tabular}

BWG: brisk walking group; MTWG: moderate tempo walking group; CG: control group 


\section{Exercise program}

Before beginning the training process, all participants of the EGs completed a 1-week walking of low-intensity physical training to ensure familiarity with the experimental procedures. Eight-week walking program of two different intensities was performed on an outdoor track $(400 \mathrm{~m}), 3$ days/week, under the control of exercise specialists, in accordance with the principles of the American College of Sports Medicine (ACSM) recommendations (1). The exercise intensity was determined using the Karvonen equation:

$$
\left[\left(\mathrm{HR}_{\text {maximum }}-\mathrm{HR}_{\text {rest }}\right) \times(0.50-0.55 / 0.70-0.75)+\mathrm{HR}_{\text {rest }}\right]
$$

BMG members started to walk $30 \mathrm{~min}$, and with 3-min increments they reached $39 \mathrm{~min}$ at the end of the first 4 weeks, at $70 \%$ heart rate reserve (HRR). On the next 4 weeks, they walked up to $51 \mathrm{~min}$ at $75 \%$ HRR. MTWG walked in the same duration, but at 50\% HRR for the first 4 weeks and 55\% HRR for the second 4 weeks. Their heart rate (HR) readings were taken by Polar Pacer heart rate monitors (Polar Vantage, Kempele, Finland) at least three times to comply with the training intensity (walking speed), and their rate of perceived exertion (RPE) was also taken using a 15-point RPE scale. RPE scores and HRs were recorded on training logs. Each exercise session started with 5-min warm-up and ended with 5-min cool-down period.

\section{Blood analysis}

Venous blood samples were collected from an antecubital vein $(9 \mathrm{ml})$ in the sitting position after a 20-min rest between 8:00 and 10:00 a.m. following a $12 \mathrm{~h}$ overnight fast. Serum was separated by centrifugation, and samples were stored at $-80{ }^{\circ} \mathrm{C}$ until assays were performed (within 2 months) in all samples. Red blood cell (RBC) counts, Hct, and blood $\mathrm{Hb}$ concentrations were determined by conventional methods using a COULTER ${ }^{\circledR}$ LH 780 Hematology Analyzer (Beckman-Coulter, Fullerton, CA, USA). The concentrations of serum iron and total iron binding capacity (TIBC) were determined by Beckman Olympus AU 5800 auto-analyzer with dedicated kits (Beckman-Coulter). Transferrin saturations were calculated via the formula (serum iron $\times 100 /$ TIBC). Follicle-stimulating hormone $(\mathrm{FSH})$ and ferritin analyses were performed using chemiluminescent immunoassay technique on Beckman UniCel DxI 800 auto-analyzer with dedicated kits. Inter-assay coefficients of variation (CVs) were obtained from actual quality control data of Dokuz Eylül University Hospital Central Laboratory that has been accredited with the ISO 15189. Inter-assay CVs (\%) determined for RBC, Hct, Hb, iron, TIBC, FSH, and ferritin were 0.5, 0.67, 0.59, 1.90, 3.87, 4.35, and 5.86, respectively. Serum IL-6 levels were determined via enzyme immunoassay methods using commercial kits (eBioscience, Vienne, Austria). The average CV precisions intra- and interassay are $3.4 \%$ and $5.2 \%$, respectively.

Serum pro-hepcidin was determined using an ELISA kit (Sunred, Shanghai, China) in accordance with the manufacturer's protocol. This assay detects the $12.5-3,600 \mathrm{ng} / \mathrm{ml}$ range of pro-hepcidin, a prohormone form of the hormone. The average CV precisions intra- and inter-assay are $<8 \%$ and $<10 \%$, respectively. Serum transferrin was determined using an ELISA kit (Enzo Life Sciences, Farmingdale, NY, USA) in accordance with the manufacturer's protocol. The average CV precisions intra- and inter-assay are $4.8 \%$ and $8.5 \%$, respectively. 


\section{Statistical analysis}

Data were analyzed using SPSS package program (version 15.0) non-parametric tests because of low numbers of subjects in different groups. Changes among the study groups were compared via the Kruskal-Wallis test; the difference between the two groups was determined using Mann-Whitney $U$ test. Bonferroni correction was made followed by Mann-Whitney $U$ test. The differences between pre- and post-data of the intervention period were determined using the Wilcoxon test. All comparisons were considered statistically significant at $p<0.05$, except the difference between two groups. Statistically significant level between the two groups was considered at $p<0.0167$ owing to Bonferroni correction $(0.05 / 3=p<0.0167)$.

\section{Results}

At the pre-study evaluation, the subjects did not differ significantly in terms of age, baseline body weight, body fat (Table I), and serum iron and ferritin (Table II) levels. BWG members had an average HR of $\sim 143.28 \pm 8.37$ beats $/ \mathrm{min}$, MTWG members had an average HR of $\sim 126.79 \pm 4.01$ beats $/ \mathrm{min}$. The RPE reported by the BWG was $\sim 13.61 \pm 0.50$ and it was $\sim 11.72 \pm 0.41$ by the MTWG.

Table II. Changes in physical and physiological characteristics of subjects following the intervention

\begin{tabular}{|c|c|c|c|c|}
\hline Variable & $N$ & $\begin{array}{c}\text { Pre-intervention } \\
\text { median (min/max) }\end{array}$ & $\begin{array}{l}\text { Post-intervention } \\
\text { median (min/max) }\end{array}$ & $\begin{array}{c}\text { Differences median } \\
(\mathrm{min} / \mathrm{max})\end{array}$ \\
\hline \multicolumn{5}{|c|}{ Body weight (kg) } \\
\hline BWG & 11 & $69.5(60.5 / 82.8)$ & $69.3(61.6 / 79.0)$ & $-0.10(-3.8 / 1.7)$ \\
\hline MTWG & 11 & $69.1(54.0 / 104.1)$ & $66.9(54.4 / 94.1)$ & $0.20(-10.0 / 14.9)$ \\
\hline $\mathrm{CG}$ & 8 & $64.6(53.6 / 75.4)$ & $64.55(54.6 / 77.0)$ & $0.35(-6.70 / 5.60)$ \\
\hline \multicolumn{5}{|l|}{ Body fat (kg) } \\
\hline BWG & 11 & $26.0(21.5 / 34.3)$ & $25.4(22.1 / 31.9)$ & $0.00(-4.30 / 4.70)$ \\
\hline MTWG & 11 & $26.3(15.6 / 51.6)$ & $25.4(15.9 / 42.6)$ & $-1.90(-9.00 / 13.6)$ \\
\hline $\mathrm{CG}$ & 8 & $25.5(14.1 / 32.7)$ & $23.6(15.2 / 33.5)$ & $0.45(-11.0 / 1.40)$ \\
\hline \multicolumn{5}{|l|}{ BMI $\left(\mathrm{kg} \mathrm{m}^{-2}\right)$} \\
\hline BWG & 11 & $26.2(23.6 / 29.6)$ & $26.2(23.6 / 29.6)$ & $-0.00(-1.30 / 1.00)$ \\
\hline MTWG & 11 & $26.3(22.2 / 40.2)$ & $25.1(22.1 / 35.9)$ & $-0.10(-4.30 / 7.00)$ \\
\hline $\mathrm{CG}$ & 8 & $25.3(20.9 / 30.1)$ & $24.2(21.3 / 30.6)$ & $0.30(-5.70 / 0.80)$ \\
\hline \multicolumn{5}{|c|}{$\mathrm{VO}_{2 \max }(\mathrm{ml} / \mathrm{kg} / \mathrm{min})$} \\
\hline BWG & 11 & $34.1(28.5 / 39.4)$ & $40.5(35.9 / 43.4)^{* *}$ & $4.57(3.16 / 12.1)^{* * *}$ \\
\hline MTWG & 11 & $31.4(20.9 / 38.5)$ & $34.3(25.33 / 40.3)^{*}$ & $3.24(-3.04 / 4.38)$ \\
\hline CG & 8 & $23.9(14.4 / 29.3)$ & $23.8(14.2 / 28.8)$ & $-0.44(-2.33 / 6.08)$ \\
\hline
\end{tabular}

$* p<0.05$ change from baseline.

$* * p<0.01$ change from baseline.

$* * * p<0.0167$ BWG versus MTWG and CG 
Apart from $\mathrm{VO}_{2 \max }$, we could not determine any other changes in the physical and physiological characteristics of the participants. $\mathrm{VO}_{2 \max }$ increased in both EGs, favoring the BWG $(p<0.01)$; the BWG also differed from the MTWG and the CG in terms of the increase determined in $\mathrm{VO}_{2 \max }$. There were no any differences among groups in terms of other variables (Table II).

Hepcidin levels increased in the BWG $(p<0.01)$, MTWG $(p=0.05)$, and CG $(p<$ $0.05)$. Serum IL-6 decreased in the BWG and MTWG ( $p<0.05$ and $p<0.01$, respectively). While serum iron levels did not change significantly in any groups, TIBC increased significantly only in the BWG $(p<0.05)$. There was a nearly significant increase in $\mathrm{Hb}$ levels $(p=0.061)$; RBC and Hct levels increased significantly only in the BWG $(p<0.05$ and $p<0.01$, respectively). We observed no statistical within-group changes in ferritin, transferrin, and transferrin saturation levels in any of the study groups. There were no changes in terms of the differences occurred at the end of the exercise program among groups in any of the parameters, except for TIBC: BWG differed from CG significantly $(p<0.0167)$ in their TIBC levels (Table III).

\section{Discussion}

To the best of our knowledge, this is the first study of different training intensities completed in 8 weeks in the form of WE and the assessments of hepcidin, IL-6, and iron status in premenopausal women. The most outstanding finding of this study is the significant reduction observed in serum IL-6 levels of both EGs and the significant increase in TIBC, Hct, and RBC levels only in the BWG.

\section{Iron and hepcidin}

Iron is an essential element for the synthesis of $\mathrm{Hb}$ and oxygen delivery and plays a key role in the electron transport chain as well as the production of energy in mitochondria $(43,44)$. Therefore, inadequate iron stores may decrease physical performance $(2,49)$. Iron loss during exercise might occur as a result of hemolysis, hematuria, sweating, and gastrointestinal bleeding $(5,8,25,50)$. Recent research has revealed that inflammation in relation to the principal iron-regulatory hormone hepcidin, which might be an important factor in exerciseassociated iron deficiency in athletes. However, research results related to the exercisehepcidin relationship have revealed contradictory findings. The results of the acute post-exercise kinetics of hepcidin and associations with iron metabolism in athletes showed elevated hepcidin levels $24 \mathrm{~h}$ after exercise, preceded by acute increase in serum iron and inflammation parameters $(34-36,40-42,48)$. On the other hand, Karl et al. (15) showed that serum hepcidin concentrations were not affected by 9 weeks of basic combat training for female soldiers but were associated with iron status and inflammation. Similarly, 32-week Nordic walking did not trigger significant changes in blood hepcidin (16). However, Auersperger et al. (4) suggested that serum hepcidin levels were found to be reduced after 8 weeks of endurance running in women without any positive relation with inflammation. The discrepancy between the aforementioned study results and our findings might result from the differences of the exercise intensities. Our exercise intensity may not be high enough to cause reductions in hepcidin levels as in the study of Auesperger et al. (4). On the other hand, exercise volume may be as important as its intensity to affect hepcidin levels. For example, in the only study that has examined the hepcidin response to training volume, it was observed that $120 \mathrm{~min}$ of exercise performed at a relative intensity of $65 \% \mathrm{VO}_{2 \max }$ on a treadmill by 
Table III. Changes in biochemical parameters of all subjects following the intervention

\begin{tabular}{|c|c|c|c|c|}
\hline Variable & $N$ & $\begin{array}{c}\text { Pre-intervention } \\
\text { median (min/max) }\end{array}$ & $\begin{array}{c}\text { Post-intervention } \\
\text { median (min/max) }\end{array}$ & $\begin{array}{c}\text { Differences median } \\
(\mathrm{min} / \mathrm{max})\end{array}$ \\
\hline \multicolumn{5}{|c|}{ Iron $(\mu \mathrm{g} / \mathrm{dl})$} \\
\hline BWG & 11 & $65.0(25.0 / 124)$ & $81.0(39.0 / 157)$ & $15.0(-73.0 / 93.0)$ \\
\hline MTWG & 11 & $98.0(14.0 / 129)$ & $62.0(24.0 / 191)$ & $-30.0(-36.0 / 82.0)$ \\
\hline CG & 8 & $92.5(10.0 / 192)$ & $101(24.0 / 24.0)$ & $4.50(-29.0 / 59.0)$ \\
\hline \multicolumn{5}{|c|}{ TIBC $(\mu \mathrm{g} / \mathrm{dl})$} \\
\hline BWG & 11 & $347(283 / 420)$ & $385(305 / 476)^{*}$ & $34.0(12.0 / 77.0)^{* * *}$ \\
\hline MTWG & 11 & $343(275 / 428)$ & $367(291 / 494)$ & $7.00(-39.0 / 66.0)$ \\
\hline CG & 8 & $346(271 / 442)$ & $343(258 / 375)$ & $-16.0(-67.0 / 27.0)$ \\
\hline \multicolumn{5}{|c|}{ Transferrin (mg/dl) } \\
\hline BWG & 11 & $199(179 / 201)$ & $199(182 / 207)$ & $0.00(-11.2 / 14.03)$ \\
\hline MTWG & 11 & $196(182 / 206)$ & $191(185 / 202)$ & $-5.61(-16.8 / 8.42)$ \\
\hline CG & 8 & $202(185 / 213)$ & $200(182 / 210)$ & $-2.80(-30.8 / 16.8)$ \\
\hline \multicolumn{5}{|c|}{ Transferrin saturation (\%) } \\
\hline BWG & 11 & $19.0(7.00 / 38.0)$ & $20.0(9.00 / 39.0)$ & $1.00(-22.0 / 18.0)$ \\
\hline MTWG & 11 & $29.0(4.00 / 38.0)$ & $19.0(6.00 / 62.0)$ & $-2.00(-11.0 / 29.0)$ \\
\hline CG & 8 & $24.5(2.00 / 70.0)$ & $28.5(7.00 / 69.0)$ & $4.50(-6.00 / 15.0)$ \\
\hline \multicolumn{5}{|c|}{ Ferritin (ng/ml) } \\
\hline BWG & 11 & $10.3(7.60 / 31.3)$ & $11.2(7.30 / 32.6)$ & $0.90(-8.70 / 7.70)$ \\
\hline MTWG & 11 & $10.7(5.00 / 57.3)$ & $17.0(2.90 / 60.0)$ & $2.60(-18.3 / 17.9)$ \\
\hline $\mathrm{CG}$ & 8 & $10.7(6.3 / 55.5)$ & $11.2(5.00 / 26.8)$ & $0.50(-50.5 / 4.10)$ \\
\hline \multicolumn{5}{|c|}{ HGB (g/dl) } \\
\hline BWG & 11 & $12.9(11.8 / 14.4)$ & $13.2(12.3 / 15.2)$ & $0.30(-0.30 / 0.90)$ \\
\hline MTWG & 11 & $12.9(11.3 / 14.6)$ & $12.7(11.60 / 14.2)$ & $-0.20(-9.70 / 0.60)$ \\
\hline $\mathrm{CG}$ & 8 & $12.2(10.4 / 14.0)$ & $12.05(10.4 / 14.3)$ & $-0.05(-0.50 / 1.60)$ \\
\hline \multicolumn{5}{|c|}{$\operatorname{RBC}\left(10^{-6} / \mu \mathrm{l}\right)$} \\
\hline BWG & 11 & $4.37(3.55 / 4.80)$ & $4.54(3.87 / 5.20)^{*}$ & $0.26(-0.12 / 0.40)$ \\
\hline MTWG & 11 & $4.80(4.05 / 6.11)$ & $4.76(4.12 / 5.96)$ & $-0.04(-0.26 / 0.28)$ \\
\hline $\mathrm{CG}$ & 8 & $4.25(4.09 / 5.18)$ & $4.51(4.17 / 5.31)$ & $0.11(-0.03 / 0.65)$ \\
\hline \multicolumn{5}{|l|}{ Het $(\%)$} \\
\hline BWG & 11 & $39.5(36.7 / 43.4)$ & $41.7(38.9 / 47.2)^{* *}$ & $1.80(-0.40 / 3.80)$ \\
\hline MTWG & 11 & $39.7(35.4 / 44.4)$ & $39.8(35.1 / 43.7)$ & $0.30(-2.40 / 2.40)$ \\
\hline
\end{tabular}


Table III. Changes in biochemical parameters of all subjects following the intervention (Continued)

\begin{tabular}{|c|c|c|c|c|}
\hline Variable & $N$ & $\begin{array}{c}\text { Pre-intervention } \\
\text { median (min/max) }\end{array}$ & $\begin{array}{l}\text { Post-intervention } \\
\text { median (min/max) }\end{array}$ & $\begin{array}{c}\text { Differences median } \\
(\mathrm{min} / \mathrm{max})\end{array}$ \\
\hline CG & 8 & $36.6(32.6 / 42.9)$ & $37.4(34.2 / 43.4)^{*}$ & $0.80(-0.50 / 5.70)$ \\
\hline \multicolumn{5}{|c|}{ Hepcidin (ng/ml) } \\
\hline BWG & 11 & $23.4(21.2 / 156)$ & $40.4(23.6 / 164)^{* *}$ & $10.4(0.73 / 21.4)$ \\
\hline MTWG & 11 & $27.5(21.1 / 141)$ & $31.5(24.9 / 167)$ & $3.84(-6.47 / 25.6)$ \\
\hline CG & 8 & $24.3(15.2 / 91.3)$ & $30.2(25.0 / 120)^{*}$ & $7.09(0.79 / 29.1)$ \\
\hline \multicolumn{5}{|c|}{ IL-6 (pg/ml) } \\
\hline BWG & 11 & $2.27(1.48 / 4.73)$ & $1.05(0.35 / 4.34)^{*}$ & $-1.45(-3.88 / 2.18)$ \\
\hline MTWG & 11 & $2.28(1.62 / 3.86)$ & $0.93(0.56 / 1.89)^{* *}$ & $-1.28(-3.26 /-0.09)$ \\
\hline CG & 8 & $2.79(1.47 / 5.12)$ & $1.79(0.81 / 3.14)$ & $-1.28(-2.80 / 1.67)$ \\
\hline
\end{tabular}

${ }^{*} p<0.05$ change from baseline.

$* * p<0.01$ change from baseline.

$* * * p<0.0167$ BWG versus CG

physically active women triggered a significantly higher response to that observed by the same women performing the same intensity of exercise $\left(65 \% \mathrm{VO}_{2 \max }\right)$ for a duration of $60 \mathrm{~min}$ (26). In addition, our results seem concordant with the research that suggests the hepcidin response to exercise seems to be dependent on a minimum intensity of exercise at $65 \% \mathrm{VO}_{2 \max }(41)$. Thus, the increase determined in hepcidin levels in the BWG, but not in moderate tempo walking group might be as a result of the cumulative effect of acute exercises at $65 \%$ of $\mathrm{VO}_{2 \max }$. However, the increase observed in hepcidin levels in the $\mathrm{CG}$ remains unclear. Moreover, the response of hepcidin to exercise is not equivocal. For example, Roecker et al. (40) observed that in 8 out of 14 marathon runners' urine hepcidin was elevated whereas in 6 of them remained constant. According to Kortas et al. (16), the effects of training on hepcidin may be dependent on subjects' body iron status since Peeling et al. (37) reported that post-exercise hepcidin did not change in subjects whose blood ferritin was $<30 \mathrm{ng} / \mathrm{ml}$ and significantly rose in those with blood ferritin $>30 \mathrm{ng} / \mathrm{ml}$. Although initial ferritin levels of the subjects were $<30 \mathrm{ng} / \mathrm{ml}$ in this study, hepcidin showed an increment. These controversial results necessitate more studies to better clarify the factors in hepcidin-exercise relationship.

\section{IL-6 and hepcidin}

IL-6 is the major cytokine produced at a higher amount in response to exercise than other cytokines (24). It is known that strenuous exercise can cause a dramatic increase in the levels of pro-inflammatory cytokines and inflammation-responsive cytokines (29). In this study, WE generated an opposite effect in serum IL-6 levels. Instead of increments, we determined significant reductions in IL-6 levels in the EGs. This reduction in IL-6 levels in this study may be related to the intensity of our exercise program, which is not so strenuous as to cause dramatic increases in the pro-inflammatory cytokines $(24,29)$. Production of IL-6 in contracting skeletal muscles as a result of exercise leads to the exercise-induced hepcidin increase. The study by Peeling et al. (35) supports this hypothesis as it was found that 
hepcidin levels elevated $3 \mathrm{~h}$ after the peak production of IL-6 induced by exercise. On the other hand, results of the studies examining exercise-IL-6 relationship are controversial and there are several studies which demonstrated that there is no correlation between IL- 6 and hepcidin $(10,21,31)$.

\section{Erythrocytes, $\mathrm{Hb}$, and $\mathrm{Hct}$}

Exercise can increase erythropoietic activity in bone marrow $(38,47)$; however, erythrocyte numbers, $\mathrm{Hb}$ levels, and Hct values were found to be significantly decreased after intensive training $(19,47)$. The reduced iron absorption in small intestine and the decreased iron export to the circulation from parenchymal cells and macrophages might cause that reduction. However, the intensity of our exercise program did not cause such reductions; whereas, we observed significant increments in erythrocytes and Hct values. Therefore, our results provide additional data to the view indicating that exercise induces an increased iron transport from blood to bone marrow to synthesize $\mathrm{Hb}$ and erythrocytes, resulting in enhanced oxygencarrying capacity (20). Despite not being significant, the increase in $\mathrm{Hb}$ in this study is clinically important $(p<0.06)$ because baseline $\mathrm{Hb}$ levels showed increments at the end of the 8-week intervention period (from 12.9 to $13.2 \mathrm{~g} / \mathrm{dl}$ ). Gardner et al. (13) have suggested that even a $1-2 \mathrm{~g} \%$ decrease in blood $\mathrm{Hb}$ concentration may result in a $20 \%$ reduction in exercise capacity. Therefore, maintaining $\mathrm{Hb}$ amount can be recommended as an effective strategy to decrease the risk of anemia; hence, brisk walking may be a good mode of exercise for pre-menopausal women to increase $\mathrm{Hb}$ concentrations.

\section{Serum iron, transferrin saturation, and serum ferritin}

Previous research indicated significant decreases in a series of serum iron status indicators, including serum iron, transferrin saturation, and serum ferritin in both human and animal models following intensive training $(19,22,39)$. It is well known that strenuous exercise usually leads to the development of sports anemia. In an 8-week strenuous training with female athletes, ferritin values decreased below $8 \mu \mathrm{g} / \mathrm{l}$ (4). In contrast, regular and moderate exercise training might be a promising, safe, and economical method to help improve body iron status. Previous research results showed that the levels of serum iron and transferrin saturation in moderately exercised rats were significantly higher than those of the controls (20). Parallel to these findings, our relatively moderate intensity exercise program did not cause any reductions in serum iron, transferrin saturation, and serum ferritin levels. In addition, although insignificant, determining increments in iron levels (from 65.0 to $81.0 \mu \mathrm{g} / \mathrm{dl}$ ) is of clinical importance since low iron levels can profoundly alter physical work performance via a decrease in oxygen transport to exercising muscle (9).

Our findings, together with previous reports, stress the importance of examining the iron deficiency in female athletes. Athletes, trainers, and medical staff should be aware of this multifaceted issue. Simple parameters such as serum iron, ferritin, transferrin, hepcidin, and IL-6 seem sufficient to identify most of the iron deficiency in the majority of athletes. Consequently, in our 8-week prospective observational study screening moderately active females, serum IL-6 levels decreased regardless of the walking type; therefore, both walking types may be useful to prevent inflammation. However, brisk walking is advisable due to the positive changes in $\mathrm{VO}_{2 \max }$ and some iron metabolism parameters as they may contribute to prevent iron deficiency. However, the significant increase in hepcidin levels in the CG remains unclear and necessitates further studies. It is not common to expect a positive effect on iron metabolism within 2 months in a group of people who do not do exercise. Therefore, 
the increase in hepcidin which occurred in the $\mathrm{CG}$ is an expected finding. Additionally, our current understanding of the mechanisms on exercise-induced alteration of iron metabolism is not complete, and further research in terms of sampling and established or emerging biomarkers is will be useful.

\section{Acknowledgements}

The authors would like to thank Dr. Münevver Büyükyazi for her invaluable contribution during the preparation process of the manuscript. We also would like to thank the coaches and directors of the sports complex, and the participants for their engagement in this study.

\section{REFERENCES}

1. American College of Sports Medicine Position Stand: The recommended quantity and quality of exercise for developing and maintaining cardiorespiratory and muscular fitness, and flexibility in healthy adults. Med. Sci. Sports Exerc. 30(6), 975-991 (1998)

2. Anker SD, Comin Colet J, Filippatos G, Willenheimer R, Dickstein K, Drexler H, Lüscher TF, Bart B, Banasiak W, Niegowska J, Kirwan BA, Mori C, von Eisenhart Rothe B, Pocock SJ, Poole-Wilson PA, Ponikowski P, FAIR-HF Trial Investigators: Ferric carboxymaltose in patients with heart failure and iron deficiency. N. Engl. J. Med. 361, 2436-2448 (2009)

3. Antosiewicz J, Kaczor JJ, Kasprowicz K, Laskowski R, Kujach S, Luszczyk M, Radziminski L, Ziemann E: Repeated "all out" interval exercise causes an increase in serum hepcidin concentration in both trained and untrained men. Cell Immunol. 283(1-2), 12-17 (2013)

4. Auersperger I, Knap B, Jerin A, Blagus R, Lainscak M, Skitek M, Skof B: The effects of 8 weeks of endurance running on hepcidin concentrations, inflammatory parameters, and iron status in female runners. Int. J. Sport Nutr. Exerc. Metab. 22, 55-63 (2012)

5. Babic Z, Papa B, Sikirika-Bosnjakovic M, Prkacin I, Misigoj-Durakovic M, Katicic M: Occult gastrointestinal bleeding in rugby players. J. Sports Med. Phys. Fitness 41, 399-402 (2001)

6. Beard JL: Iron biology in immune function, muscle, metabolism, and neuronal functioning. J. Nutr. 131, 568-579 (2001)

7. Beard J, Tobin B: Iron status and exercise. Am. J. Clin. Nutr. 72(Suppl. 2), 594S-597S (2000)

8. DeRuisseau KC, Cheuvront SN, Haymes EM, Sharp RG: Sweat iron and zinc losses during prolonged exercise. Int. J. Sport Nutr. Exerc. Metab. 12, 428-437 (2002)

9. Diaz V, Peinado AB, Barba-Moreno L, Altamura S, Butragueño J, González-Gross M, Alteheld B, Stehle P, Zapico AG, Muckenthaler MU, Gassmann M: Elevated hepcidin serum level in response to inflammatory and iron signals in exercising athletes is independent of moderate supplementation with vitamin $\mathrm{C}$ and E. Physiol. Rep. 3(8), e12475 (2015)

10. Ferrucci L, Semba RD, Guralnik JM, Ershler WB, Bandinelli S, Patel KV, Sun K, Woodman RC, Andrews NC, Cotter RJ, Ganz T, Nemeth E, Longo DL: Proinflammatory state, hepcidin, and anemia in older persons. Blood 115(18), 3810-3816 (2010)

11. Fischer CP: Interleukin-6 in acute exercise and training: what is the biological relevance? Exerc. Immunol. Rev. 12, 6-33 (2006)

12. Ganz T, Nemeth E: Hepcidin and disorders of iron metabolism. Annu. Rev. Med. 62, 347-360 (2011)

13. Gardner GW, Edgerton VR, Senewiratne B, Barnard RJ, Ohira Y: Physical work capacity and metabolic stress in subjects with iron deficiency anemia. Am. J. Clin. Nutr. 30, 910-917 (1977)

14. Hsu SP, Ching CK, Chien CT, Hung KY: Plasma prohepcidin positively correlates with haematocrit in chronic hemodialysis patients. Blood Purif. 24, 311-316 (2006)

15. Karl JP, Lieberman HR, Cable SJ, Williams KW, Young AJ, McClung JP: Randomized, double-blind, placebocontrolled trial of an iron-fortified food product in female soldiers during military training, relations between iron status, serum hepcidin, and inflammation. Am. J. Clin. Nutr. 92, 93-100 (2010)

16. Kortas J, Prusik K, Flis D, Prusik K, Ziemann E, Leaver N, Antosiewicz J: Effect of Nordic Walking training on iron metabolism in elderly women. Clin. Interv. Aging 10, 1889-1896 (2015)

17. Kulaksiz H, Gehrke SG, Janetzko A, Rost D, Bruckner T, Kallinowski B, Stremmel W: Pro-hepcidin: expression and cell specific localisation in the liver and its regulation in hereditary haemochromatosis, chronic renal insufficiency, and renal anaemia. Gut 53, 735-743 (2004) 
18. Laukkanen R, Oja P, Pasanen M, Vuori I: Validity of a two-kilometre walking test for estimating maximal aerobic power in overweight adults. Int. J. Obes. Relat. Metab. Disord. 16(4), 263-268 (1992)

19. Liu YQ, Chang YZ, Zhao B, Wang HT, Duan XL: Does hepatic hepcidin play an important role in exerciseassociated anemia in rats? Int. J. Sport Nutr. Exerc. Metab. 21, 19-26 (2011)

20. Liu YQ, Duan XL, Chang YZ, Wang HT, Qian ZM: Molecular analysis of increased iron status in moderately exercised rats. Mol. Cell Biochem. 282, 117-123 (2006)

21. Łukaszyk E, Łukaszyk M, Koc-Żórawska E, Tobolczyk J, Bodzenta-Łukaszyk A, Małyszko J: Iron status and inflammation in early stages of chronic kidney disease. Kidney Blood Press. Res. 40, 366-373 (2015)

22. Magazanik A, Weinstein Y, Dlin RA, Derin M, Schwartzman S, Allalouf D: Iron deficiency caused by 7 weeks of intensive physical exercise. Eur. J. Appl. Physiol. Occup. Physiol. 57, 198-202 (1988)

23. Malyszko J, Mysliwiec M: Hepcidin in anemia and inflammation in chronic kidney disease. Kidney Blood Press. Res. 30, 15-30 (2007)

24. Margeli A, Skenderi K, Tsironi M, Hantzi E, Matalas AL, Vrettou C, Kanavakis E, Chrousos G, Papassotiriou I: Dramatic elevations of interleukin- 6 and acute-phase reactants in athletes participating in the ultradistance foot race spartathlon: severe systemic inflammation and lipid and lipoprotein changes in protracted exercise. J. Clin. Endocr. Metab. 90, 3914-3918 (2005)

25. McInnis MD, Newhouse IJ, von Duvillard S, Thayer R: The effect of exercise intensity on hematuria in healthy male runners. Eur. J. Appl. Physiol. Occup. Physiol. 79, 99-105 (1998)

26. Mettler S, Zimmermann MB: Iron excess in recreational marathon runners. Eur. J. Clin. Nutr. 64, 490-494 (2010)

27. Nemeth E, Tuttle MS, Powelson J, Vaughn MB, Donovan A, Ward DMV, Ganz T, Kaplan J: Hepcidin regulates cellular iron efflux by binding to ferroportin and inducing its internalization. Science 306, 2090-2093 (2004)

28. Nikolaidis MG, Michailidis Y, Mougios V: Variation of soluble transferrin receptor and ferritin concentrations in human serum during recovery from exercise. Eur. J. Appl. Physiol. 89(5), 500-502 (2003)

29. Ostrowski K, Rohde T, Asp S, Schjerling P, Pedersen BK: Pro- and anti-inflammatory cytokine balance in strenuous exercise in humans. J. Physiol. 515(Pt. 1), 287-291 (1999)

30. Ostrowski K, Rohde T, Zacho M, Asp S, Pedersen BK: Evidence that interleukin-6 is produced in human skeletal muscle during prolonged running. J. Physiol. 508, 949-953 (1998)

31. Paköz ZB, Çekiç C, Arabul M, Yüksel ES, İpek S, Vatansever S, Ünsal B: An evaluation of the correlation between hepcidin serum levels and disease activity in inflammatory bowel disease. Gastroenterol. Res. Pract. 2015, 810942 (2015)

32. Pedersen BK: Muscles and their myokines. J. Exp. Biol. 214(Pt. 2), 337-346 (2011)

33. Peeling P, Dawson B, Goodman C, Landers G, Trinder D: Athletic induced iron deficiency: new insights into the role of inflammation, cytokines and hormones. Eur. J. Appl. Physiol. 103(4), 381-391 (2008)

34. Peeling P, Dawson B, Goodman C, Landers G, Wiegerinck ET, Swinkels DW, Trinder D: Cumulative effects of consecutive running session on hemolysis, inflammation and hepcidin activity. Eur. J. Appl. Physiol. 106, 51-59 (2009)

35. Peeling P, Dawson B, Goodman C, Landers G, Wiegerinck ET, Swinkels DW, Trinder D: Effects of exercise on hepcidin response and iron metabolism during recovery. Int. J. Sport Nutr. Exerc. Metab. 19, 583-597 (2009)

36. Peeling P, Dawson B, Goodman C, Landers G, Wiegerinck ET, Swinkels DW, Trinder D: Training surface and intensity: inflammation, hemolysis, and hepcidin expression. Med. Sci. Sports Exerc. 41, 1138-1145 (2009)

37. Peeling P, Sim M, Badenhorst CE, Dawson B, Abbiss CR, Swinkels DW, Trinder D: Iron status and the acute post-exercise hepcidin response in athletes. PLoS One 9(3), e93002 (2014)

38. Qian ZM, Xiao DS, Tang PL, Yao FY, Liao QK: Increased expression of transferrin receptor on membrane of erythroblasts in strenuously exercised rats. J. Appl. Physiol. 87, 523-529 (1999)

39. Reinke S, Taylor WR, Duda GN, von Haehling S, Reinke P, Volk HD, Anker SD, Doehner W: Absolute and functional iron deficiency in professional athletes during training and recovery. Int. J. Cardiol. 156, 186-191 (2012)

40. Roecker L, Meier-Buttermilch R, Bretchel L, Nemeth E, Ganz T: Iron-regulatory protein hepcidin is increased in female athletes after a marathon. Eur. J. Appl. Physiol. 95, 569-571 (2005)

41. Sim M, Dawson B, Landers G, Swinkels DW, Tjasma H, Trinder D, Peeling P: Effect of exercise modality and intensity on postexercise interleukin-6 and hepcidin levels. Int. J. Sport Nutr. Exerc. Metab. 23, 178-186 (2013)

42. Sim M, Dawson B, Landers G, Wiegerinck ET, Swinkels DW, Townsend MA, Trinder D, Peeling P: The effects of carbohydrate ingestion during endurance running on post-exercise inflammation and hepcidin levels. Eur. J. Appl. Physiol. 12, 1289-1298 (2012) 
43. Speich M, Pineau A, Ballereau F: Minerals, trace elements and related biological variables in athletes and during physical activity. Clin. Chim. Acta 312, 1-11 (2001)

44. Stoltzfus RJ: Iron-deficiency anemia: reexamining the nature and magnitude of the public health problem. Summary: implications for research and programs. J. Nutr. 131, 697S-700S; discussion 700S-701S (2001)

45. Taes YEC, Wuyts B, Boelaert JR, Vriese AS, Delanghe JR: Prohepcidin accumulates in renal insufficiency. Clin. Chem. Lab. Med. 42, 387-389 (2004)

46. Taheri N, Roshandel GH, Mojerloo M, Hadad M, Mirkarimi H, Nejad RK, Joshaghani H: Comparison of serum levels of hepcidin and pro-hepcidin in hemodialysis patients and healthy subjects. Saudi J. Kidney Dis. Transpl. 26(1), 34-38 (2015)

47. Tian Y, Zhao J, Zhao B, Gao Q, Xu J, Liu D: The ratio of sTfR/ferritin is associated with the expression level of TfR in rat bone marrow cells after endurance exercise. Biol. Trace Elem. Res. 147, 261-266 (2012)

48. Troadec MB, Lainé F, Daniel V, Rochcongar P, Ropert M, Cabillic F, Perrin M, Morcet J, Loréal O, Olbina G, Westerman M, Nemeth E, Ganz T, Brissot P: Daily regulation of serum and urinary hepcidin is not influenced by submaximal cycling exercise in humans with normal iron metabolism. Eur. J. Appl. Physiol. 106, 435-443 (2009)

49. Williams MH: Dietary supplements and sports performance, minerals. J. Int. Soc. Sports Nutr. 2, $43-49$ (2005)

50. Zoller H, Vogel W: Iron supplementation in athletes - first do no harm. Nutrition 20, 615-619 (2004) 